\title{
Global runoff anomalies over 1993-2009 estimated from coupled Land-Ocean-Atmosphere water budgets and its relation with climate variability
}

\author{
S. Munier ${ }^{1}$, H. Palanisamy ${ }^{1}$, P. Maisongrande ${ }^{1}$, A. Cazenave ${ }^{1}$, and E. F. Wood $^{2}$ \\ ${ }^{1}$ Laboratoire d'études en géophysique et océanographie spatiales, UMR5566, LEGOS/CNES/CNRS/IRD/UPS, \\ Toulouse, France \\ ${ }^{2}$ Department of Civil and Environmental Engineering, Princeton University, Princeton, NJ, USA \\ Correspondence to: S. Munier (simon.munier@gmail.com)
}

Received: 14 March 2012 - Published in Hydrol. Earth Syst. Sci. Discuss.: 11 April 2012

Revised: 3 August 2012 - Accepted: 13 September 2012 - Published: 16 October 2012

\begin{abstract}
Whether the global runoff (or freshwater discharge from land to the ocean) is currently increasing and the global water cycle is intensifying is still a controversial issue. Here we compute land-atmosphere and ocean-atmosphere water budgets and derive two independent estimates of the global runoff over the period 1993-2009. Water storage variations in the land, ocean and atmosphere reservoirs are estimated from different types of data sets: atmospheric reanalyses, land surface models, satellite altimetry and in situ ocean temperature data (the difference between altimetry based global mean sea level and ocean thermal expansion providing an estimate of the ocean mass component). These data sets are first validated using independent data, and then the global runoff is computed from the two methods. Results for the global runoff show a very good correlation between both estimates. More importantly, no significant trend is observed over the whole period. Besides, the global runoff appears to be clearly impacted by large-scale climate phenomena such as major ENSO events. To infer this, we compute the zonal runoff over four latitudinal bands and set up for each band a new index (combined runoff index) obtained by optimization of linear combinations of various climate indices. Results show that, in particular, the intertropical and northern mid-latitude runoffs are mainly driven by ENSO and the Atlantic multidecadal oscillation (AMO) with opposite behavior. Indeed, the zonal runoff in the intertropical zone decreases during major El Niño events, whereas it increases in the northern mid-latitudes, suggesting that water masses over land are shifted northward/southward during El Niño/La
\end{abstract}

Niña. In addition to this study, we propose an innovative method to estimate the global ocean thermal expansion. The method is based on the assumption that the difference between both runoff estimates is mainly due to the thermal expansion term not accounted for in the estimation of the ocean mass. We find that our reconstructed thermal expansion time series compares well with two existing data sets in terms of year-to-year fluctuations but somewhat differs on longer (multi-year) time scales. Possible explanations include non negligible steric variations from the deep ocean.

\section{Introduction}

Continental waters are continuously exchanged with atmosphere and oceans through vertical and horizontal mass fluxes (precipitation, evaporation, transpiration of the vegetation, surface runoff and underground flow). Freshwater discharge from land to ocean (or global runoff) is a key component of the global water cycle. Its variability reflects the continental hydrological dynamics and is then impacted by climate change (e.g. intensification of precipitation over land) and anthropogenic activities (reservoirs, land use changes, irrigation, groundwater pumping). As noted by many authors (e.g. Labat, 2004; Huntington, 2006; Gerten et al., 2008; Dai et al., 2009), global runoff may be seen as an indicator of the intensification of the hydrological cycle. Besides, since global runoff represents an integrated response to continental hydrological dynamics, it has also been used to detect the 
impact of anthropogenic activities (e.g. Gleick, 2003; Nilsson et al., 2005; Milliman et al., 2008).

Numerous studies have focused on the characteristics of global runoff, in terms of long term mean, trends, spatial distribution and interannual variability. The most basic way to estimate global runoff is the use of gauged based measurements of river discharge at the outlets of the world's major basins. Databases such as the Global Runoff Data Centre (GRDC) provide such data for a large number of gauge stations worldwide. Although this approach gives the most direct estimation of global runoff, it remains limited by some important drawbacks (see e.g. Legates et al., 2005; Peel and McMahon, 2006 or Syed et al., 2009 for detailed discussions), among which are the following:

- Many regions remain unmonitored. For instance, Fekete et al. (2002) provided global runoff estimates from the 663 major river basins, which represent $71 \%$ of the global runoff. Milliman et al. (2008) used data from 131 river basins, representing $51 \%$ of the global runoff.

- The time periods covered by gauge stations are very irregular in terms of start and end time and gaps in observations.

- Alternative pathways (direct groundwater flows, floodplain inundation, deltaic regions, etc.) are not accounted for.

- Data sharing remains often difficult because of economic and geopolitical constraints and the density of gauge network is decreasing (Shiklomanov et al., 2002).

To counterpart these drawbacks, some authors proposed to use hydrological models (with associated errors and uncertainties) rather than or in combination with in situ data (Trenberth et al., 2007; Dai et al., 2009; Alkama et al., 2011; Haddeland et al., 2011).

An alternative method consists in solving the water budget at the global scale, while distinguishing three main compartments: land, ocean and atmosphere. The latter may be separated into the region over land (land atmosphere) and its complementary part (ocean atmosphere). Figure 1 schematizes water stocks and fluxes involved in the global water cycle. The following equations describe the land (1), ocean (2) and atmosphere (3) global water budgets, respectively (Peixoto and Oort, 1992).

$$
\begin{aligned}
\frac{\partial S_{1}}{\partial t} & =P_{1}-E_{1}-R \\
\frac{\partial S_{\mathrm{o}}}{\partial t} & =P_{\mathrm{o}}-E_{\mathrm{o}}+R \\
\frac{\partial W_{1 / \mathrm{o}}}{\partial t} & =E_{1 / \mathrm{o}}-P_{1 / \mathrm{o}}-\operatorname{div}\left(Q_{1 / \mathrm{o}}\right)
\end{aligned}
$$

where $S_{1}$ represents the terrestrial water storage, $S_{0}$ the ocean mass, $R$ the global runoff, $P$ the precipitation, $E$ the

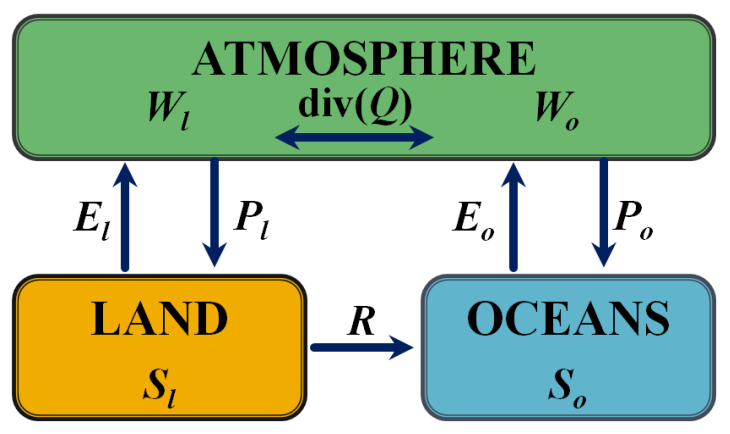

Fig. 1. Stocks and fluxes in the global water cycle. Refer to the text for a detailed description of the variables. $S_{1}$ represents the terrestrial water storage, $S_{\mathrm{o}}$ the ocean mass, $R$ the global runoff, $P$ the precipitation, $E$ the evapo(transpi)ration, $W$ the total column water vapor and $\operatorname{div}(Q)$ the divergence of the vertically integrated water vapor flux. Subscripts 1 and o designate the spatial average over land and ocean, respectively.

evapo(transpi)ration, $W$ the total column water vapor and $\operatorname{div}(Q)$ the divergence of the vertically integrated water vapor flux. Subscripts 1 and o designate the spatial average over land and ocean, respectively.

The global runoff may be estimated directly from the land or ocean water budgets (Eqs. 1-2) (see e.g. Seo et al., 2009 or Syed et al., 2010), then involving estimations of $P$ and $E$. Even though precipitation data benefit from dense observation networks (ground based and remotely sensed), it may suffer from large uncertainties in some sparsely monitored regions. Moreover, very few direct measurements of evapotranspiration exist (flux towers) and modeling $E$ at the global scale is subject to large uncertainties (Vinukollu et al., 2011). The atmospheric water budget has been introduced by some authors (e.g. Oki et al., 1995; Oki, 1999; Syed et al., 2009) to overcome difficulties in estimating $P$ and $E$. Dai and Trenberth (2002) showed that the use of the atmospheric water budget improved model based estimates of global runoff.

For the past decade, the ocean mass and the terrestrial water storage can be provided by the Gravity Recovery and Climate Experiment (GRACE) (Tapley et al., 2004; Wahr et al., 2004) space gravimetry mission, as done for instance by Syed et al. (2009) for $S_{1}$. Before its launch in 2002, no direct measurements of $S_{1}$ and $S_{0}$ were available and since it was difficult to validate estimates from models, variations in water storage were usually neglected (e.g. Oki, 1999; Dai and Trenberth, 2002) then leading to an estimation of the global runoff directly from the net precipitation $(P-E)$. Nevertheless, Syed et al. (2009) showed the importance of taking this term into account by using GRACE estimates of $S_{1}$.

GRACE products are available since 2002, which may limit the time span of the study to the last decade. Alternatively, Land Surface Models (LSMs) provide monthly estimations of $S_{1}$ with a satisfactory accuracy at basin to global scales, as shown in the various studies comparing GRACE 
and LSMs (see Ramillien et al., 2008 for a review of studies prior to 2008). The covered period of LSMs depends on the model, but simulations generally run at least over the last two decades. Besides, the ocean mass $S_{0}$ may be derived from satellite radar altimetry observations, which provide estimations of the global mean sea level (GMSL), and from in situ hydrographic data. To derive the ocean mass variations, GMSL has to be corrected from the steric component (effect of temperature and salinity), as done by, for example, Syed et al. (2010).

In this study, we use the coupled land-ocean-atmosphere water budgets to estimate the interannual variability of global runoff. Two estimates are computed: one from the land/atmosphere coupling (Eq. 4) and the other from the ocean/atmosphere coupling (Eq. 5).

$$
\begin{aligned}
R_{1} & =-\frac{\partial W_{1}}{\partial t}-\operatorname{div}\left(Q_{1}\right)-\frac{d S_{1}}{\mathrm{~d} t} \\
R_{\mathrm{O}} & =\frac{\partial W_{\mathrm{o}}}{\partial t}+\operatorname{div}\left(Q_{\mathrm{o}}\right)+\frac{d S_{\mathrm{O}}}{\mathrm{d} t} .
\end{aligned}
$$

$S_{1}$ is estimated from three LSMs, $S_{0}$ from altimetry based GMSL and the net precipitation term (time derivative of $W$ and $\operatorname{div}(Q))$ from atmospheric reanalyses. Considering the level of uncertainties on each term appearing in the above equations, each data set used to compute the global runoff is cross-validated with independent data. Besides, since altimetry observations are used, our global runoff estimates cover the altimetry time span (1993-2009). This study expands the previous ones by providing for the first time a comparison of global runoff estimates from land and ocean water budgets, in terms of interannual variability, over the last two decades.

Section 2 presents the data sets used in this study, whereas results are presented in Sects. 3, 4 and 5. In Sect. 3, each data set is compared with independent data to ensure its reliability and to give an idea of its uncertainties. The comparison between both global runoff estimates, in terms of interannual variability, is given in Sect. 4. Our global runoff estimate is also compared with global climate indices (ENSO related SOI, AMO). A discussion on the ocean thermal expansion used in the estimation of the ocean mass and an innovative method to estimate it are provided in Sect. 5.

\section{Data and models used in this study}

In this section, we present the data and models used to compute global runoff by the two methods $\left(R_{1}\right.$ and $R_{\mathrm{O}}$ from Eqs. 4-5). Data used for validation purposes are also presented.

\subsection{Altimetry-based sea level data}

For the altimetry-based sea level data, we use the DT-MSLA "Ref" series provided by Collecte Localisation Satellite (CLS; http://www.aviso.oceanobs.com/en/data/products/ sea-surface-height-products/global/msla/index.html). This data set is used over the time span from January 1993 to December 2009. It is available as $0.25^{\circ} \times 0.25^{\circ}$ Mercator projection grids at weekly interval from a combination of several altimetry missions (Topex/Poseidon, Jason-1 and 2, Envisat and ERS 1 and 2). Most recently improved geophysical corrections are applied to the sea level data (see Ablain et al., 2009, for details). The weekly sea level grids are geographically averaged between $65^{\circ} \mathrm{S}$ and $65^{\circ} \mathrm{N}$ to obtain a GMSL time series. The data are further averaged on a monthly basis.

\subsection{Steric data}

Steric sea level is estimated using the updated in situ ocean temperature and salinity data from Ishii and Kimoto (2009), v6.12 (called hereafter IK09). The IK09 temperature data are corrected for the XBT depth bias. The temperature and salinity data are available at monthly intervals over 16 depth levels ranging from the ocean surface down to $700 \mathrm{~m}$ depth, on a global $1^{\circ} \times 1^{\circ}$ grid from 1955 to 2009 . Steric sea level anomalies are computed over the $0-700 \mathrm{~m}$ depth range for the period January 1993 to December 2009. The deep ocean contribution cannot be accounted for since hydrographical data below $700 \mathrm{~m}$ are too sparse. Recent studies have shown that in terms of trend, the deep ocean contributes by $\sim 10 \%$ to the total steric effect (Church et al., 2011). Besides, almost all interannual variability in steric sea level is confined in the upper $300-500 \mathrm{~m}$ of the ocean (e.g. Llovel et al., 2011). At global scale, salinity does not contribute to the GMSL and is therefore neglected in the following.

\subsection{Land Surface Models}

To estimate the terrestrial water storage component $\left(S_{1}\right)$, we use monthly gridded outputs of three different LSMs: (1) the WaterGAP Global Hydrology Model (WGHM) (Döll et al., 2003); (2) the Interactions between Soil, Biosphere and Atmosphere - Total Runoff Integrating Pathways (ISBA-TRIP) model (Alkama et al., 2011; Decharme et al., 2010); and (3) the Land Dynamics (LaD) model (Milly and Shmakin, 2002). WGHM outputs are available through December 2009, whereas ISBA ends in December 2008 and $\mathrm{LaD}$ in July 2007. Discrepancies among $S_{1}$ derived from the different LSMs may come from differences in the numerical schemes and meteorological forcing. As noted by Syed et al. (2009), discrepancies among models outputs provide an estimation of the model uncertainties.

Independently, the evapotranspiration modeled by the three LSMs is used for the validation of net precipitation over land $\left(P_{1}-E_{1}\right)$ computed from the atmospheric water budget (Eq. 3). 


\subsection{GRACE data}

To validate LSMs derived $S_{1}$ and altimetry-based $S_{0}$, a comparison with GRACE data is proposed in Sect. 3. Here we use GRACE products (release 2) for the period 2003-2009 (with missing data for June 2003), computed by the Groupe de Recherche de Géodesie Spatiale (GRGS) (Bruinsma et al., 2010). It consists of monthly $1^{\circ} \times 1^{\circ}$ gridded time series of water volume $\left(S_{1}\right.$ or $\left.S_{\mathrm{o}}\right)$, expressed in terms of equivalent water height $(\mathrm{EWH})$. At each grid mesh, the volume anomalies are obtained by removing the temporal mean. The GRGS data are stabilized during the generation process so that no smoothing or filtering is necessary. When GRACE data is used at basin scales, it has to be corrected from leakage effects due to its low resolution (Longuevergne et al., 2010). Nevertheless, such effects have minor impact at the global scale and GRACE data is not corrected here.

As said previously, GRACE provides reliable estimations of spatiotemporal water volume variations since 2002 and it would have been possible to complete GRACE data with LSMs outputs and altimetry based ocean mass for the period 1993-2002. In order to keep consistency in our computations over 1993-2009, we prefer not to use GRACE products to estimate terrestrial water storage and ocean mass variations. Nevertheless, in both cases, comparison with GRACE observations is performed to increase confidence in data.

\subsection{Meteorological data}

Data used in this study to compute P-E from the atmospheric water budget ( $W$ and $\operatorname{div}(Q))$ are based on reanalysis products from the European Centre for Medium-Range Weather Forecast (ECMWF) ERA-Interim data set (Dee et al., 2011). These are daily global data provided on $1.5^{\circ} \times 1.5^{\circ}$ grids in units of $\mathrm{mm} \mathrm{day}^{-1}$. All gridded data are further expressed in terms of monthly averages over the period 1993-2009.

For validation purposes, we also consider six global precipitation data sets: Global Precipitation Climatology Centre (GPCC, Schneider et al., 2008), Climatic Research Unit (CRU, available online at http://badc.nerc.ac.uk/data/ $\mathrm{cru} /$ ), the Willmott-Matsuura product (WM, Willmott and Matsuura, 2010), Global Precipitation Climatology Project (GPCP, Adler et al., 2003), Climate Prediction Center (CPC) Merged Analysis of Precipitation (CMAP, Xie and Arkin, 1997), the Princeton Global Forcing (PGF, Sheffield et al., 2006). These data sets are obtained either from ground based observations (GPCC, CRU, WM) or from merged ground based and satellite observations (GPCP, CMAP, PGF).

\section{Processing and evaluation of the data and models}

\subsection{Data processing}

As the focus of this study is the interannual variability of the global runoff, the seasonal component of each signal presented in the following is removed. This component is obtained by fitting two sinusoidal signals periods of 6 and 12 months. Moreover, although the mean value of the global runoff is still subject to discussions (see e.g. Syed et al., 2009, and references therein), it is not in the scope of this paper. Hence, the temporal mean is also removed from the global runoff estimates. In Eqs. (5)-(6), $S_{1}$ and $S_{0}$ are derivated with respect to time and any trend in $S_{1}$ and $S_{0}$ would lead to constants in the runoff. Consequently, $S_{1}$ and $S_{0}$ are detrended in the following. Note that detrending $S_{1}$ and $S_{\mathrm{o}}$ does not impact the runoff trend since change in storage (i.e. first order differencing) filters out linear trends.

As a spherical harmonics $(\mathrm{SH})$ truncation at degree 50 (resolution of $400 \mathrm{~km}$ ) is applied on GRACE data to obtain water mass variations, we applied the same $\mathrm{SH}$ truncation to LSM outputs for a more relevant comparison between GRACE and LSMs derived $S_{1}$ (as suggested by many authors, e.g. Longuevergne et al., 2010). SH truncation is applied only for the model validation, not for the runoff computation.

Finally, all graphs showing temporal evolution of the spatial mean of any variable have been smoothed using a 3months moving average.

\subsection{Land/Ocean masks: estimate of the high latitudes contribution}

As indicated above, altimetry products used here are available only in the $65^{\circ} \mathrm{S}-65^{\circ} \mathrm{N}$ domain. Moreover, ice sheets (Greenland and Antarctica) are generally not modeled in LSMs because of their very specific hydrological behavior, all the more so as very few in situ data are available in these regions and the models' validation is then quite difficult. Hence ice sheets and high latitude oceans are excluded from the present study. Figure $2 \mathrm{a}$ shows the land and ocean regions considered here.

The exclusion of ice sheets and high latitude oceans has no major consequences in the following since these regions only play a minor role in the interannual variability of global runoff. To assess this, Fig. 2 b and c presents $S_{1}$ and $S_{\mathrm{o}}$ variations derived from GRACE over the four regions shown in Fig. 2a. Despite significant trends in water mass variations - not shown in the graphs - in ice sheets $\left(-160 \mathrm{~km}^{3} \mathrm{yr}^{-1}\right)$ and high latitude oceans $\left(-66 \mathrm{~km}^{3} \mathrm{yr}^{-1}\right)$, these regions are scarcely involved in the global water cycle in terms of interannual variability.

\subsection{Comparison of terrestrial water storage from GRACE and LSMs}

Figure 3a shows the total water storage derived from the LSMs; the blue shading represents the root mean square (RMS) deviation of each model with respect to the average. The RMS between LSMs is $1.26 \mathrm{~mm}$, which is quite low compared to the amplitude of the interannual variations of $S_{1}$. 


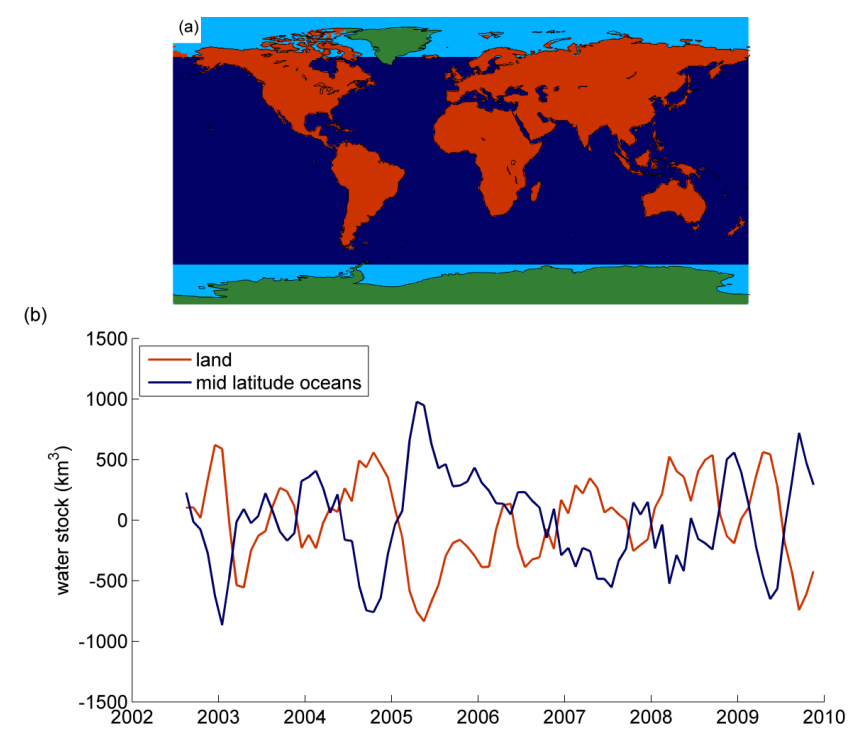

(c)

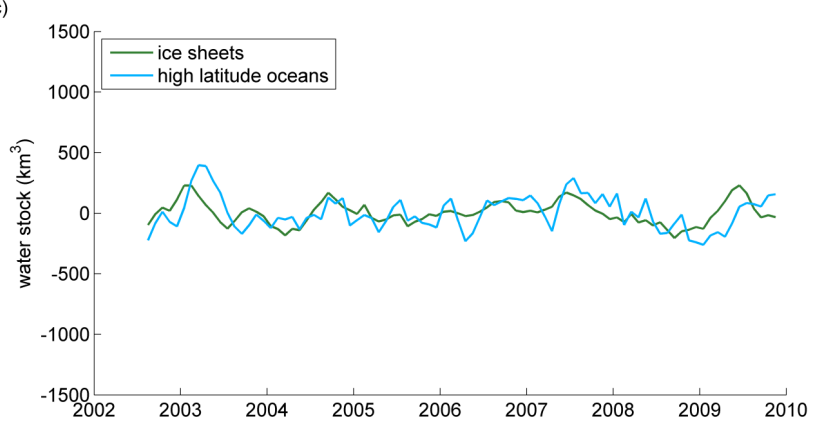

Fig. 2. (a) Land and ocean masks (high latitude Arctic and Antarctic oceans in light blue and ice sheets in green). (b) Detrended interannual variations of GRACE derived water stocks in land (except ice sheets) and oceans (except high latitudes). (c) Detrended interannual variations of GRACE derived water stocks in ice sheets and high latitude oceans.

The comparison with GRACE over 2002-2009 is shown in the lower right corner (the trend of LSMs $S_{1}$ over the GRACE period has been removed for the purpose of this comparison). The good agreement between the independent LSMs and GRACE derived $S_{1}$ (correlation coefficient of 0.66) reinforces the reliability of both estimates. Figure $3 b$ presents the spatial distribution of the RMS differences between both estimates. Main differences are localized in the intertropical zone and more specifically in the Amazon and Congo basins. Two main reasons may explain this: (1) the hydrological cycle has greater amplitude in these basins than in others leading to higher RMS and (2) GRACE errors are larger near the equator than in high latitudes (Swenson and Wahr, 2006). High RMS between GRACE and LSMs are also found in glacier regions (Alaska, Scandinavia, Himalaya) which may come from the fact that, contrarily to GRACE, LSMs generally do not account for glaciers. These discrepancies are of

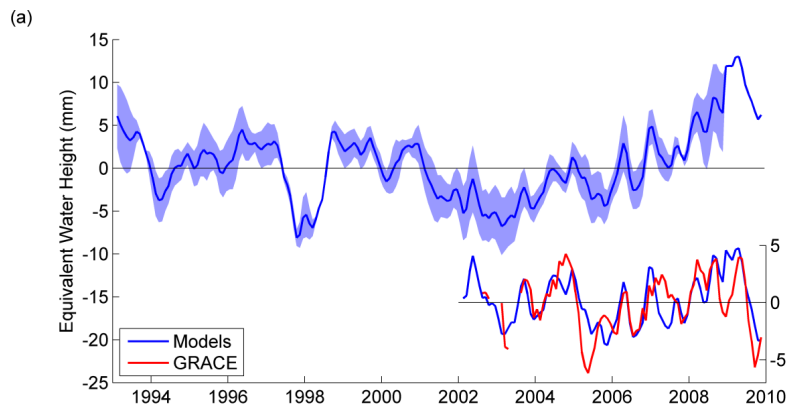

(b)

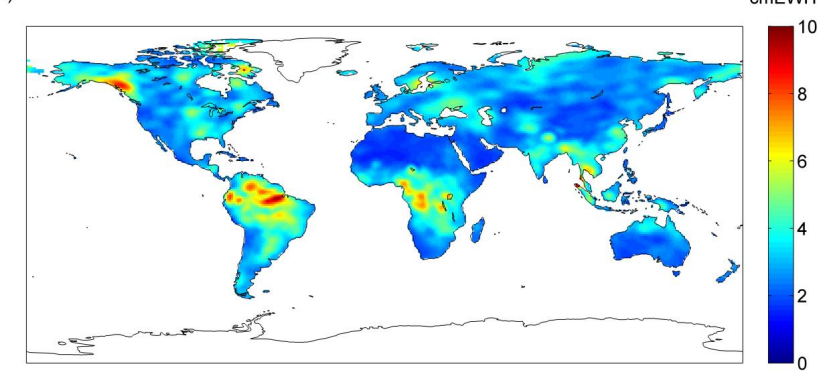

Fig. 3. (a) Terrestrial water storage interannual variations from models and GRACE. Blue shading represents discrepancies between models. (b) Mean RMS over 2002-2009 between GRACE and LSMs terrestrial water storage.

less importance in terms of volume since pixel area tends to 0 in high latitudes.

\subsection{Ocean mass estimate}

Global mean sea level (GMSL) variations are the result of variations in the ocean mass $\left(S_{\mathrm{o}}\right)$ and in the steric component. Salinity has little effect at the global scale so that the remaining steric component corresponds to the ocean thermal expansion (TE). Ocean mass variations are then derived from GMSL variations corrected from TE according to Eq. (6).

$S_{\mathrm{o}}=\mathrm{GMSL}-\mathrm{TE}$

Figure 4 presents the ocean mass variations $S_{0}$ derived from GRACE and computed from GMSL, corrected or not from the thermal expansion TE. The thermal expansion correction over 2002-2005 clearly deteriorates the correlation with GRACE derived $S_{\mathrm{O}}$ (correlation coefficient of 0.17 and 0.45 , respectively with and without correction, for the common period 2002-2009). In particular, the TE correction leads to a great negative peak in 2003-2004 that is not shown in GRACE $S_{\mathrm{o}}$. Considering the mitigated efficiency of the TE correction, we prefer not to apply it for the runoff computation done in Sect. 4. Nevertheless, we will come back to this issue in Sect. 5. 


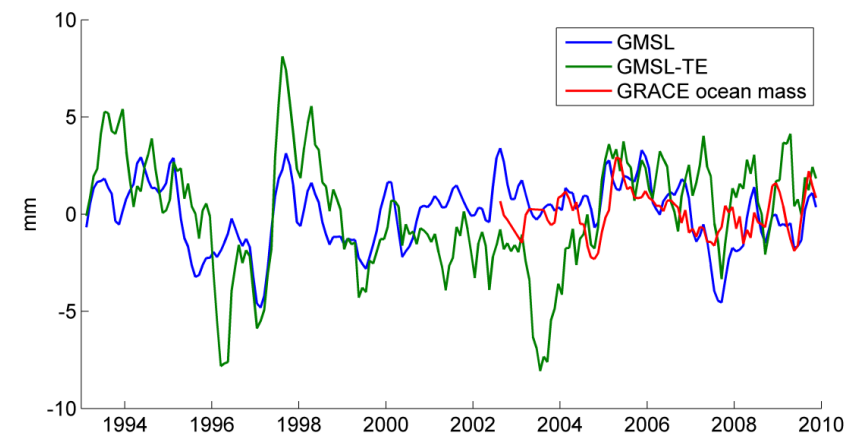

Fig. 4. Comparison of global mean sea level (GMSL) computed from altimetry, GMSL corrected from the thermal expansion TE and GRACE ocean mass.

\section{5 $P-E$ over land and atmospheric water budget}

Figure 5a shows net precipitation over land $\left(P_{1}-E_{1}\right)$ computed from the atmospheric water budget (Eq. 3) and ERAInterim data. This graph shows a sudden increase in $P_{1}-E_{1}$ in 2003. The difference between the temporal mean over 19932002 and the one over 2003-2009 equals $3 \mathrm{~mm} \mathrm{month}^{-1}$, which is of the same order of magnitude as the interannual variability. We are currently investigating the causes of this important shift, but we suspect a change in input data in the ERA-Interim procedure. Namely radiance measurements from AIRS have been assimilated since July 2003, which may have an impact on the global water cycle (P. Poli, personal communication, 2011). To assess the artificial origin of the discontinuity, we compare $P_{1}-E_{1}$ from ERA-Interim with independent precipitation and evapotranspiration data sets (see Sect. 2). We use the outputs of the three LSMs presented previously (ISBA, WGHM and LaD) to estimate evapotranspiration. The blue curve and blue shading in Fig. 5b show the mean and standard deviation of the 18 computed time series of $P_{1}-E_{1}$. The observed $P_{1}$ minus modeled $E_{1}$ is very similar to the ERA-Interim estimate before 2003 but it has not present any shift since 2003, which reinforces the assumption of an artificial origin of the discontinuity. We then decided to correct ERA-Interim $P_{1}-E_{1}$ by adding a constant offset over the period 2003-2009. The value of the offset is obtained by minimizing the difference between ERA-Interim $P_{1}-E_{1}$ and observed $P_{1}$ minus modeled $E_{1}$. The optimum offset value $\left(-2.78 \mathrm{~mm} \mathrm{month}^{-1}\right)$ leads to a very good correlation between the two estimates.

The same analysis may have been done over oceans but very few evaporation data over ocean exist and comparison between two of the main existing data sets (OA-Flux, Yu and Weller, 2007 and HOAPS, Andersson et al., 2007) shows large discrepancies in terms of interannual variability (Fig. 6). Besides, Fig. 7 represents the interannual variations of $\operatorname{div}(Q)$ and $d W / \mathrm{d} t$ over oceans and land. Note that the discontinuity correction (offset of $-2.78 \mathrm{~mm} \mathrm{month}^{-1}$ ) (a)

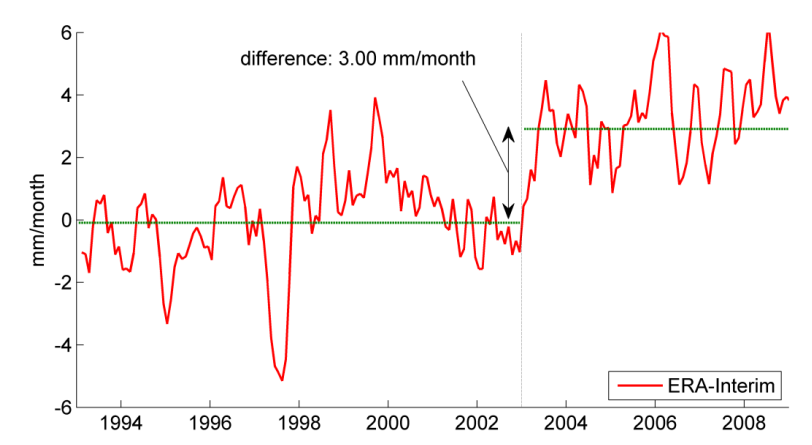

(b)

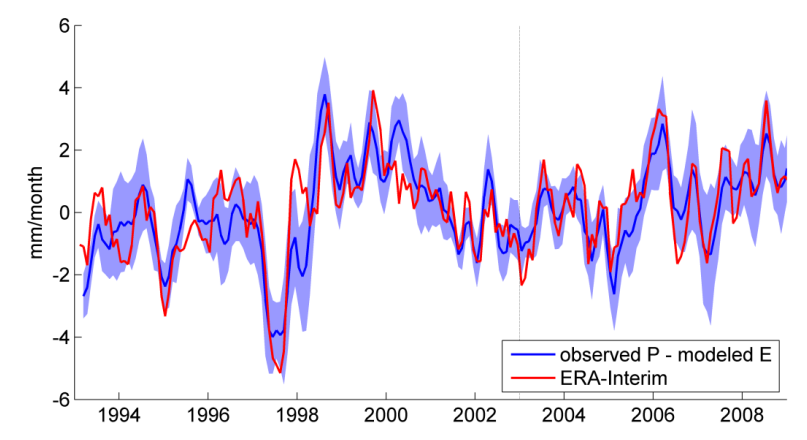

Fig. 5. (a) Interannual variability of precipitation minus evapotranspiration over land $\left(P_{1}-E_{1}\right)$ computed from the atmospheric water budget and ERA-Interim data. (b) Corrected $P_{1}-E_{1}$ with a uniform offset of $-2.78 \mathrm{~mm} \mathrm{month}^{-1}$ over 2003-2009, and observed $P_{1}$ minus modeled $E_{1}$ used to find the optimum offset (blue shading represents discrepancies between $P_{1}-E_{1}$ obtained from the different the data sets).

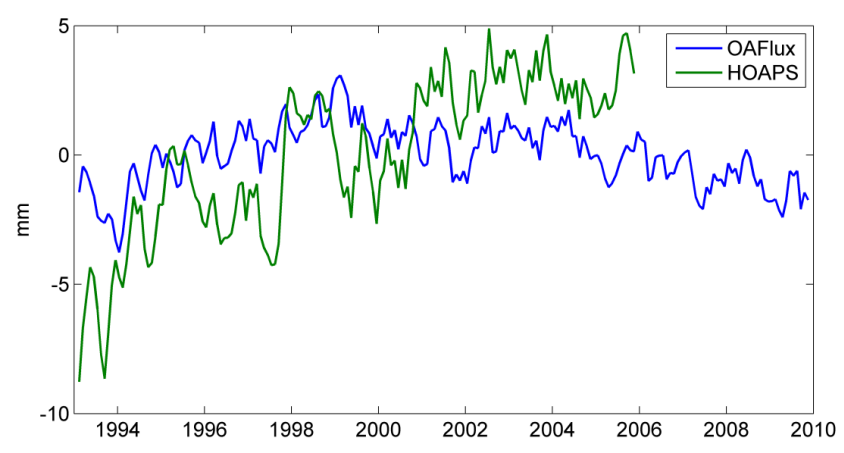

Fig. 6. Interannual variability of evaporation over ocean from OAFlux and HOAPS.

has been applied in $\operatorname{div}(Q)$ over land and oceans. First, it is shown that $d W / \mathrm{d} t$ plays a minor role in the interannual variability of the global water cycle. Second, $\operatorname{div}\left(Q_{1}\right)$ is very similar to $-\operatorname{div}\left(Q_{0}\right)$ which means that very little water is horizontally exchanged between high- and mid-latitude regions of the atmosphere (separated by the $65^{\circ} \mathrm{S}$ and $65^{\circ} \mathrm{N}$ parallels). These considerations lead to $P_{1}-E_{1}=-\left(P_{0}-E_{0}\right)$. In that sense, the same offset is applied in the estimation of $P_{\mathrm{o}}-E_{\mathrm{o}}$. 


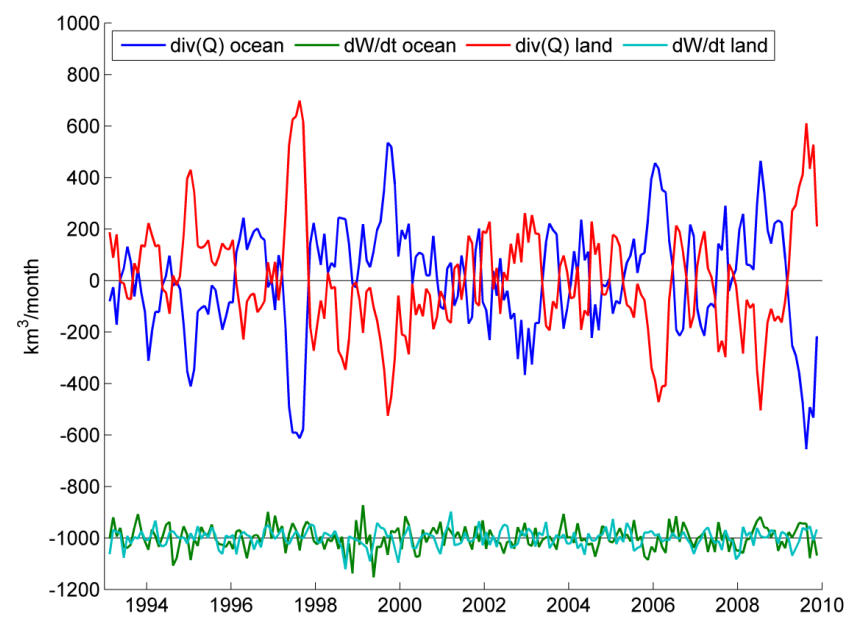

Fig. 7. Components of the atmospheric water budget. Spatial mean over ocean and land. The $d W / \mathrm{d} t$ time series are shifted vertically for clarity.

\section{Global runoff and climate variability}

\subsection{Comparison of the two global runoff estimates}

The comparison between estimates of the global runoff from the land-atmosphere and the ocean-atmosphere water budgets is shown in Fig. 8. Both estimates are very well correlated (correlation coefficient of 0.73 , mean standard deviation of $63 \mathrm{~km}^{3} \mathrm{month}^{-1}$ ). Interannual variations of global runoff ranges from about -200 to $200 \mathrm{~km}^{3}$ month $^{-1}$, with higher peaks during major ENSO events. In particular, negative peaks in 1994-1995, 1997-1998 and 2009-2010 are related to lower than normal precipitation over land during El Niño events, whereas the positive peak in 1999-2000 is related to higher than normal land precipitation during La Niña event. One can notice that the 1997-1998 El Niño event is clearly visible on Fig. 3a, which shows a great negative peak in $S_{1}$ during this period, a result of lower/higher precipitation intensity over land/ocean (Gu et al., 2007). The ENSO effects on precipitation over land and oceans is also shown on Fig. 7.

Besides, no significant trend is observed over the whole period. Indeed, the trend equals $48 \mathrm{~km}^{3} \mathrm{month}^{-1}$ per decade for $R_{1}$ and $72 \mathrm{~km}^{3}$ month $^{-1}$ per decade for $R_{\mathrm{o}}$, which is negligible compared to the mean standard deviation of $R_{1}$ and $R_{\mathrm{O}}$ (169 and $228 \mathrm{~km}^{3} \mathrm{month}^{-1}$, respectively). These values are quite lower than the one found by Syed et al. (2010) $\left(540 \mathrm{~km}^{3} \mathrm{yr}^{-2}\right.$ or $450 \mathrm{~km}^{3}$ month ${ }^{-1}$ per decade) but are in agreement with results of some other previous studies (Dai et al., 2009; Milliman et al., 2008) which found insignificant trends. The difference with Syed et al. (2010) may be partly explained by the fact that the authors computed the trend over 1995-2006 and that the global runoff presents higher values before 1995 and lower values after 2006, leading to a

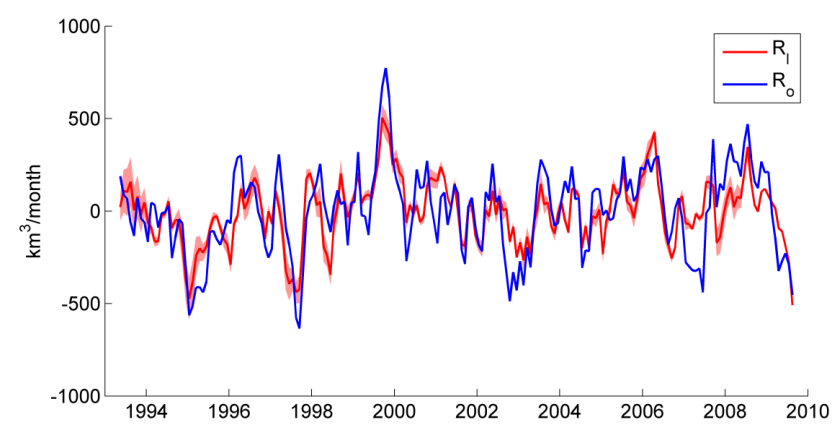

Fig. 8. Comparison of runoff computed from land-atmosphere $\left(R_{1}\right)$ and ocean-atmosphere $\left(R_{\mathrm{O}}\right)$ water budgets. The red shading represents discrepancies relative to the different considered LSMs.

reduction of the global trend. Indeed, with the methodology developed in this study, the global runoff trend over the period 1995-2006 equals $128 \mathrm{~km}^{3}$ month $^{-1}$ per decade for $R_{1}$ and $143 \mathrm{~km}^{3}$ month $^{-1}$ per decade for $R_{\mathrm{o}}$. While these values are higher than for the period 1993-2009, they are still lower than the value obtained by Syed et al. (2010). The difference likely comes from the different data sets used to compute $P$ $E$ over oceans. Namely, Syed et al. (2010) considered two estimates of $E_{\mathrm{O}}$ (OA-Flux and HOAPS) which are quite different in terms of interannual variability (Fig. 6).

Other authors (Dai et al., 2009; Alkama et al., 2011) found non negligible trends over some of the major river basins for the last decades, but these trends seem to compensate against each other at the global scale.

The differences between $R_{1}$ and $R_{\mathrm{O}}$ may be explained by two main factors: modeling errors and TE not accounted for in the ocean mass estimation. Concerning the former, considering three different LSMs help us to quantify modeling errors. We find a mean standard deviation of $43 \mathrm{~km}^{3} \mathrm{month}^{-1}$ due to LSMs discrepancies (represented by the red shading in Fig. 8), which is very low compared to the interannual variability of $R$. This suggests that the differences between $R_{1}$ and $R_{\mathrm{O}}$ are mainly explained by the fact that the ocean mass is not corrected from TE. Nevertheless, the good correlation between $R_{\mathrm{O}}$ and $R_{\mathrm{l}}$ shows that TE plays a minor role in the interannual variability of global runoff. In Sect. 5, we investigate a new method to estimate the ocean thermal expansion component by using the difference $R_{0}-R_{1}$.

\subsection{Zonal runoff and correlation with climate indices}

As said previously, the global runoff seems to be highly impacted by major ENSO events. Many studies, including Dai et al. (2009), Syed et al. (2010) and Labat (2010), also showed this particular link. In addition, Gu et al. (2007) reported high correlations between ENSO and land precipitation in the intertropical zone and lower but not null correlations in mid- and high latitudes. In this section, we propose 
to investigate the correlation between the zonal runoff and different global scale climate phenomena.

First, the zonal runoff is computed over four latitudinal bands separated by the $60^{\circ} \mathrm{N}, 20^{\circ} \mathrm{N}$ and $20^{\circ} \mathrm{S}$ parallels (solid lines in Fig. 9). As expected, while the intertropical zone contributes for the most part to the interannual variability of the global runoff, northern high latitude and southern mid latitude zonal runoffs are quite negligible.

For each zone, the zonal runoff is then compared with different linear combinations of several climate indices. The indices considered here are the following: the Multivariate ENSO Index (MEI), the Atlantic multidecadal oscillation (AMO), the Pacific Decadal Oscillation (PDO), the PacificNorth America teleconnection (PNA) and the Arctic Oscillation index (AO). The reader may refer to Rossi et al. (2011) for a detailed presentation of these indices. For each subset of one or two indices, the linear combination is optimized by maximizing the correlation between the zonal runoff and the combined index. Subsets that give the best results are used to compute a new index called combined runoff index (CRI). Optimization results are given, for each zonal band, by Eq. (7) (climate indices have been normalized before the optimization).

$$
\begin{aligned}
\mathrm{CRI}(-60 /-20) & =0.53 \times \mathrm{PDO}+0.47 \times \mathrm{AMO} \\
\mathrm{CRI}(-20 /+20) & =-0.62 \times \mathrm{MEI}-0.38 \times \mathrm{AMO} \\
\mathrm{CRI}(+20 /+60) & =0.54 \times \mathrm{MEI}+0.46 \times \mathrm{AMO} \\
\mathrm{CRI}(+60 /+90) & =0.73 \times \mathrm{PNA}+0.27 \times \mathrm{AO}
\end{aligned}
$$

Since LSMs and ERA-Interim outputs are available since 1980 or earlier (apart from WGHM which is only available since 1992), we also compared CRI and zonal $R_{1}$ over the period 1980-1992, period not used in the calibration of CRI. Figure 9 shows (dashed lines) results of calibration (period 1993-2009) and validation (period 1980-1992); CRI has been normalized to match the range of zonal runoffs variability. The two numbers in the brackets in the legend represent the correlation between zonal $R_{1}$ and CRI for the calibration period and for the overall period, respectively. Figure 9 clearly shows a very good correlation for the intertropical zone (namely during the validation period) and more contrasted correlations in mid- and high latitudes.

Not surprisingly, MEI contributes for the most part in the intertropical and northern mid-latitude zonal runoffs. For these two zonal runoffs, AMO also plays an important role. Figure 9 and Eq. (7) show that these two zonal runoffs are highly anti-correlated, namely with higher/lower runoffs than normal in mid-latitude/intertropical zones during major ElNiño events (e.g. in 1983 or in 1998). The reciprocal is true for La-Niña events (e.g. in 1989 or in 2000). This suggests that during El-Niño events, while water mass is shifted westward from the South American continent to the tropical Pacific Ocean (Gu et al., 2007), it is also shifted northward to mid-latitude continents. Besides, ENSO seems to play a less important role in northern high latitudes and southern

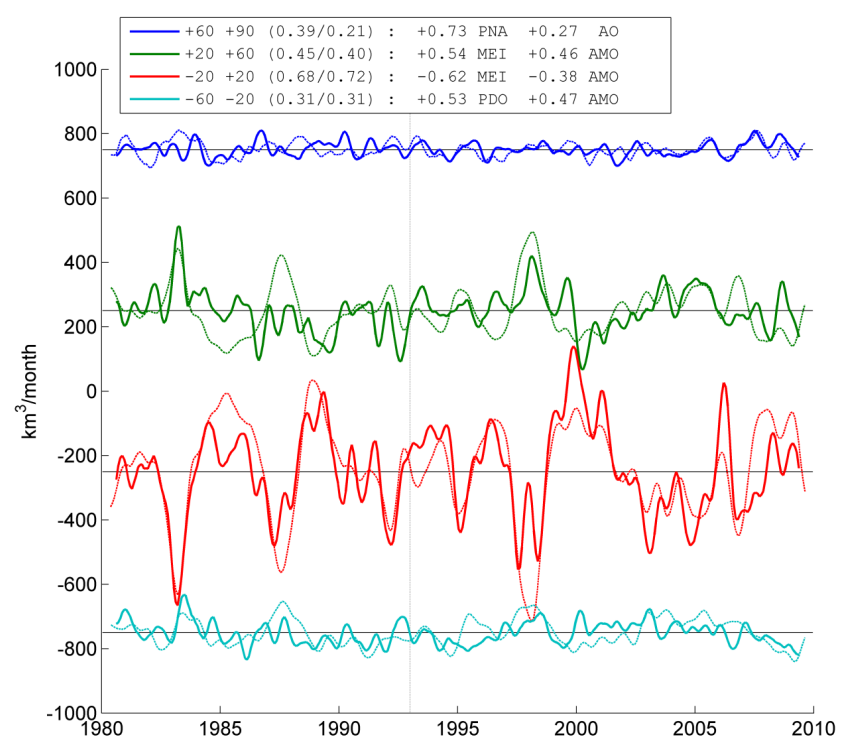

Fig. 9. Comparison of zonal runoff computed from landatmosphere-water budgets ( $R_{1}$, solid lines) and combined runoff in$\operatorname{dex}\left(\mathrm{CRI}\right.$, dashed lines) over northern high latitudes $\left(60^{\circ} \mathrm{N}-90^{\circ} \mathrm{N}\right)$, northern mid-latitudes $\left(20^{\circ} \mathrm{N}-60^{\circ} \mathrm{N}\right)$, intertropical zone $\left(20^{\circ} \mathrm{S}-\right.$ $\left.20^{\circ} \mathrm{N}\right)$ and southern mid-latitudes $\left(60^{\circ} \mathrm{S}-20^{\circ} \mathrm{S}\right)$. For each zone, time series are shifted vertically for clarity. CRI has been normalized to match the range of global runoff variability. The two numbers in the brackets represent the correlation between $R_{1}$ and CRI for the calibration period (1993-2009) and the whole period, respectively. Results of calibration (climate indices and related coefficients) are given in the legend box.

mid-latitudes. Northern high latitude zonal runoff is logically governed by northern mid- to high latitude climate phenomena (Pacific-North America teleconnection and Arctic Oscillation). For each of the three other zones, CRI is a combination of a climate index related to the Pacific Ocean and another related to the Atlantic Ocean.

Further investigations are suggested to complete these preliminary results, namely about the relationship between the zonal runoff and climate indices characteristics in the frequency domain (Rossi et al., 2011).

\section{Reconstruction of the ocean thermal expansion}

In this subsidiary section, we come back to the aforementioned problem of the ocean thermal expansion (TE) correction and propose an innovative method to reconstruct this component of the global mean sea level. Indeed, as said previously, the observed difference between $R_{1}$ and $R_{\mathrm{O}}$ may be mainly attributed to TE. Assuming that $P_{1}-E_{1}=-\left(P_{0^{-}}\right.$ $E_{\mathrm{o}}$ ) (see Sect. 3.5) and combining Eqs. (1)-(2) leads to $S_{1}+S_{0}=$ constant. Then combining this last equation with Eq. (6) leads to the following estimate of TE (after removing the constant): 
$\mathrm{TE}=\mathrm{GMSL}+S_{\mathrm{l}}$.

We further compare our TE reconstruction with TE data from two different databases: the IK09 (presented in Sect. 2.2) and the WOD09 (Levitus et al., 2009). The WOD09 and IK09 databases account for depth-bias corrections on XBT temperature data (e.g. Wijffels et al., 2008). The TE data from the two databases are publicly available at: http://www.noaa.gov/ for WOD09 and http://atm-phys.nies.go.jp/ ism/pub/ProjD/ v6.9/ for IK09. For each database, we computed the thermosteric sea level on a $1^{\circ} \times 1^{\circ}$ grid at monthly interval since 1993, integrating temperature anomalies from the surface down to $700 \mathrm{~m}$. For that purpose, we first computed density anomalies at each standard level down to $700 \mathrm{~m}$ by considering temperature anomalies and using the classical equation of state of the ocean. Then, we integrated density anomalies at each grid point and each time step to obtain the thermosteric sea level (Gill, 1982).

Figure 10 compares TE obtained from our reconstruction and from IK09 (a) and WOD09 (b). Noting a 3 months lag between our reconstruction and the two other curves - which cause is still under investigation - we have accounted for this delay in Fig. 10. The comparison shows that our TE reconstruction has similar high frequency (i.e. year-to-year) behavior as IK09 and WOD09 time series, but significantly differs at lower frequency (multi-year variability). In addition to the uncertainties of each time series, the difference with our TE estimate may arise from that deep ocean contribution (below $700 \mathrm{~m}$ ) that is inherently accounted for in our TE is not accounted for in IK09 and WOD09 data. Even though we expect deep ocean contribution to be small (see Sect. 2.2), it may have a low frequency behavior that could explain the differences with our reconstruction.

Anyway, one may note that the differences between our reconstruction and each data set are of the same order as the difference between IK09 and WOD09. Concerning the period 2003-2004, this comparison seems to confirm an overestimation of TE derived from IK09 and WOD09 already noted in Sect. 3.4 and Fig. 4. To corroborate or invalidate this overestimation, we are presently performing a specific study about the origin of such discrepancies over this period (comparison with TE derived from global circulation models).

\section{Conclusions}

The impacts of climate change and anthropogenic factors on the global water cycle represent a critical and timely issue. Namely, the question about an intensification of the global water cycle is highly debated and the answers are still controversial. Evidence of such intensification may be derived by looking at different parameters of the water cycle, e.g. an increase in global runoff $(R)$, with potential (a)

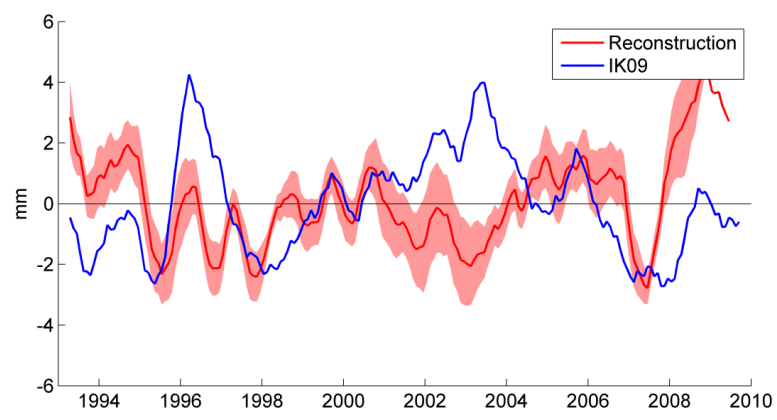

(b)

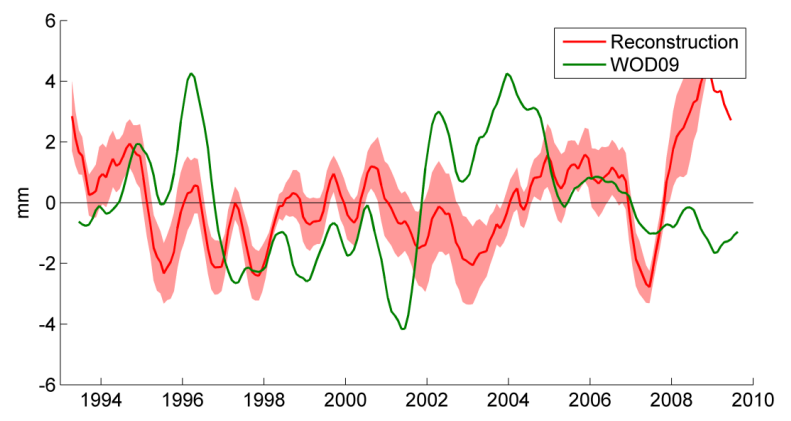

Fig. 10. Comparison of the interannual variations of the thermal expansion obtained from this study and from (a) Ishii and $\mathrm{Ki}$ moto (2009) v6.12 (IK09) and (b) Levitus et al. (2009) (WOD09). Red shading represents discrepancies due to LSMs. Note that the reconstructed time series have been shifted by 3 months forward.

implications on basin scale water management. Here we investigated two methods to estimate $R$ over the period 19932009. Both methods are derived from the coupling of the land-atmosphere and ocean-atmosphere water budgets, respectively. Independent data sets are used to estimate water storage variations in each compartment: atmospheric reanalyses, land surface models, satellite altimetry and in situ ocean temperature data. Each component of the water budget is first cross-validated using other independent data sets, such as GRACE for ocean mass and terrestrial water storage. Concerning the global runoff estimated from the two coupled water budgets, the two main results are

- both estimates correlate very well over the study time span (correlation coefficient of 0.73), giving confidence in the method;

- no significant trend is observed over the whole period (the trend ranges from 48 to $72 \mathrm{~km}^{3}$ month $^{-1}$ per decade, which is insignificant compared to the mean standard deviation of $R$ ranging from 169 to $228 \mathrm{~km}^{3}$ month $^{-1}$ ).

Results also show that major ENSO events largely impact the global runoff (decrease/increase during El Niño/La Niña). To infer the link between global runoff and climate variability, we computed the zonal runoff over 4 latitudinal 
bands (intertropical zone, northern and southern midlatitudes and northern high latitudes) and compared it with different climate indices. We then set up a combined runoff index (CRI) obtained for each zone by optimization of climate indices linear combinations. We showed that CRI well correlates with the zonal runoff even over a validation period not used for the optimization, especially for the intertropical zone, which contributes for the most part in the global runoff. Besides, linear coefficients resulting from the optimization provide information about which large-scale climate phenomena are the main drivers for each zonal runoff. Namely, the intertropical and northern mid-latitude zonal runoffs are mainly driven by ENSO and AMO. Moreover, the zonal runoffs in these two zones are anti-correlated, particularly during ENSO events. This suggests that water masses are shifted northward/southward during major El Niño/La Niña events.

Lastly, the difference between the two runoff estimates may be mainly explained by the ocean thermal expansion (TE) term which has not been accounted for in the ocean mass estimate. Consequently, we used our runoff reconstruction to propose an innovative method for providing a new estimate of TE. The comparison with two existing data sets shows a quite good agreement in terms of interannual variability, showing the relevance of the method, but points out a period (2003-2004) during which ocean thermal expansion data may be in error.

More generally, these results have implications for studies on the global water cycle, with the underlying issues of global warming and water resources availability. Namely, we show that an intensification of the global water cycle due to the global warming is not obvious over the last two decades. Besides, as large scale climate phenomena may be seen as drivers of the zonal (or regional) runoffs, analyzing their evolution with climate change should provide indicators of potential evolutions of the global runoff. The mechanisms relating such phenomena and runoff need to be addressed in further studies.

Acknowledgements. We would like to acknowledge Andreas Güntner (GFZ German Research Centre for Geosciences) and Bertrand Decharme (CNRM, MeteoFrance) for sharing WGHM and ISBA outputs, respectively. S. Munier and H. Palanisamy received a grant from the Centre National d'Etudes Spatiales (CNES, France) and from ANR Cecile, respectively. We are also grateful to the two anonymous reviewers who helped us to improve the paper.

Edited by: H. Cloke

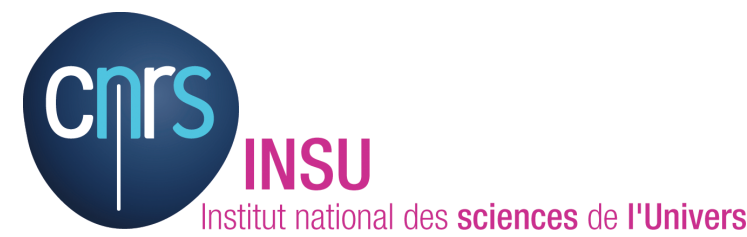

The publication of this article is financed by CNRS-INSU.

\section{References}

Ablain, M., Cazenave, A., Valladeau, G., and Guinehut, S.: A new assessment of the error budget of global mean sea level rate estimated by satellite altimetry over 1993-2008, Ocean Sci., 5, 193201, doi:10.5194/os-5-193-2009, 2009.

Adler, R. F., Huffman, G. J., Chang, A., Ferraro, R., Xie, P. P., Janowiak, J., Rudolf, B., Schneider, U., Curtis, S., Bolvin, D., Gruber, A., Susskind, J., Arkin, P., and Nelkin, E: The version2 global precipitation climatology project (GPCP) monthly precipitation analysis (1979-present), J. Hydrometeorol., 4, 11471167, 2003.

Alkama, R., Decharme, B., Douville, H., and Ribes, A.: Trends in Global and Basin-Scale Runoff over the Late Twentieth Century: Methodological Issues and Sources of Uncertainty, J. Climate, 24, 3000-3014, doi:10.1175/2010JCLI3921.1, 2011.

Andersson, A., Bakan, S., Fennig, K., Grassl, H., Klepp, C., and Schulz, J.: Hamburg Ocean Atmosphere Parameters and Fluxes from Satellite Data - HOAPS-3 - monthly mean, World Data Center for Climate, electronic publication, 2007.

Bruinsma, S., Lemoine, J. M., Biancale, R., and Vales, N.: CNES/GRGS 10-day gravity field models (release 2) and their evaluation, Adv. Space Res., 45, 587-601, doi:10.1016/j.asr.2009.10.012, 2010.

Church, J. A., White, N. J., Konikow, L. F., Domingues, C. M., Cogley, J. G., Rignot, E., Gregory, J. M., van den Broeke, M. R., Monaghan, A. J., and Velicogna, I.: Revisiting the Earth's sea-level and energy budgets from 1961 to 2008, Geophys. Res. Lett., 38, L18601, doi:10.1029/2011GL048794, 2011.

Dai, A. and Trenberth, K. E.: Estimates of Freshwater Discharge from Continents: Latitudinal and Seasonal Variations, J. Hydrometeorol., 3, 660-687, 2002.

Dai, A., Qian, T. T., Trenberth, K. E., and Milliman, J. D.: Changes in Continental Freshwater Discharge from 1948 to 2004, J. Climate, 22, 2773-2792, doi:10.1175/2008JCLI2592.1, 2009.

Decharme, B., Alkama, R., Douville, H., Becker, M., and Cazenave, A.: Global Evaluation of the ISBA-TRIP Continental Hydrological System, Part II: Uncertainties in River Routing Simulation Related to Flow Velocity and Groundwater Storage, J. Hydrometeorol., 11, 601-617, doi:10.1175/2010JHM1212.1, 2010.

Dee, D. P., Uppala, S. M., Simmons, A. J., Berrisford, P., Poli, P., Kobayashi, S., Andrae, U., Balmaseda, M. A., Balsamo, G., Bauer, P., Bechtold, P., Beljaars, A. C. M., van de Berg, L., Bidlot, J., Bormann, N., Delsol, C., Dragani, R., Fuentes, M., Geer, A. J., Haimberger, L., Healy, S. B., Hersbach, H., Holm, E. V., Isaksen, L., Kallberg, P., Koehler, M., Matricardi, M., McNally, A. P., Monge-Sanz, B. M., Morcrette, J. J., Park, B. K., Peubey, C., de Rosnay, P., Tavolato, C., Thepaut, J. N., and Vitart, F.: The ERA-Interim reanalysis: configuration and performance of the 
data assimilation system, Q. J. Roy. Meteor. Soc., 137, 553-597, doi:10.1002/qj.828, 2011.

Doll, P., Kaspar, F., and Lehner, B.: A global hydrological model for deriving water availability indicators: model tuning and validation, J. Hydrol., 270, 105-134, 2003.

Fekete, B. M., Vorosmarty, C. J., and Grabs, W.: High-resolution fields of global runoff combining observed river discharge and simulated water balances, Global Biogeochem. Cy., 16, 1042, doi:10.1029/1999GB001254, 2002.

Gerten, D., Rost, S., von Bloh, W., and Lucht, W.: Causes of change in 20th century global river discharge, Geophys. Res. Lett., 35, L20405, doi:10.1029/2008GL035258, 2008.

Gill, A. E.: Atmosphere-Ocean Dynamics, Academic Press, San Diego, 1982.

Gleick, P.: Global freshwater resources: Soft-path solutions for the 21st century, Science, 302, 1524-1528, doi:10.1126/science.1089967, 2003.

Gu, G., Adler, R. F., Huffman, G. J., and Curtis, S.: Tropical rainfall variability on interannual-to-interdecadal and longer time scales derived from the GPCP monthly product, J. Climate, 20, 40334046, doi:10.1175/JCLI4227.1, 2007.

Haddeland, I., Clark, D. B., Franssen, W., Ludwig, F., Voß, F., Arnell, N. W., Bertrand, N., Best, M., Folwell, S., Gerten, D., Gomes, S., Gosling, S. N., Hagemann, S., Hanasaki, N., Harding, R., Heinke, J., Kabat, P., Koirala, S., Oki, T., Polcher, J., Stacke, T., Viterbo, P., Weedon, G. P., and Yeh, P.: Multi-Model Estimate of the Global Terrestrial Water Balance: Setup and First Results, J. Hydrometeorol., 12, 869-884, doi:10.1175/2011JHM1324.1, 2011.

Huntington, T. G.: Evidence for intensification of the global water cycle: Review and synthesis, J. Hydrol., 319, 83-95, 2006.

Ishii, M. and Kimoto, M.: Reevaluation of historical ocean heat content variations with time-varying XBT and MBT depth bias corrections, J. Oceanogr., 65, 287-299, doi:10.1007/s10872-0090027-7, 2009.

Labat, D.: Evidence for global runoff increase related to climate warming, Adv. Water Resour., 27, 631-642, doi:10.1016/j.advwatres.2004.02.020, 2004.

Labat, D.: Cross wavelet analyses of annual continental freshwater discharge and selected climate indices, J. Hydrol., 385, 269-278, doi:16/j.jhydrol.2010.02.029, 2010.

Legates, D., Lins, H., and Mccabe, G.: Comments on "Evidence for global runoff increase related to climate warming" by Labat et al., Adv. Water Resour., 28, 1310-1315, doi:10.1016/j.advwatres.2005.04.006, 2005.

Levitus, S., Antonov, J. I., Boyer, T. P., Locarnini, R. A., Garcia, H. E. and Mishonov, A. V.: Global ocean heat content 1955-2008 in light of recently revealed instrumentation problems, Geophys. Res. Lett., 36, L07608, doi:10.1029/2008GL037155, 2009.

Llovel, W., Meyssignac, B., and Cazenave, A.: Steric sea level variations over 2004-2010 as a function of region and depth: Inference on the mass component variability in the North Atlantic Ocean, Geophys. Res. Lett., 38, L15608, doi:201110.1029/2011GL047411, 2011.

Longuevergne, L., Scanlon, B. R., and Wilson, C. R.: GRACE Hydrological estimates for small basins: Evaluating processing approaches on the High Plains Aquifer, USA, Water Resour. Res., 46, W11517, doi:10.1029/2009WR008564, 2010.
Milliman, J. D., Farnsworth, K. L., Jones, P. D., Xu, K. H., and Smith, L. C.: Climatic and anthropogenic factors affecting river discharge to the global ocean, 1951-2000, Global Planet. Change, 62, 187-194, doi:10.1016/j.gloplacha.2008.03.001, 2008.

Milly, P. C. D. and Shmakin, A. B.: Global modeling of land water and energy balances. Part I: the land dynamics (LaD) model, J. Hydrometeorol., 3, 283-299, 2002.

Nilsson, C., Reidy, C., Dynesius, M., and Revenga, C.: Fragmentation and flow regulation of the world's large river systems, Science, 308, 405-408, doi:10.1126/science.1107887, 2005.

Oki, T.: The global water cycle, Global Energy and Water Cycles, edited by: Browning, K. A. and Gurney, R. J., Cambridge University Press, 10-29, 1999.

Oki, T., Musiake, K., Matsuyama, H., and Masuda, K.: Global atmospheric water balance and runoff from large river basins, Hydrol. Process., 9, 655-678, doi:10.1002/hyp.3360090513, 1995.

Peel, M. C. and McMahon, T. A.: Continental Runoff: A qualitycontrolled global runoff data set, Nature, 444, E14-E14, doi:10.1038/nature05480, 2006.

Peixoto, J. P. and Oort, A. H.: Physics of climate, Springer, 1992.

Ramillien, G., Famiglietti, J., and Wahr, J.: Detection of Continental Hydrology and Glaciology Signals from GRACE: A Review, Surv. Geophys., 29, 361-374, 2008.

Rossi, A., Massei, N., and Laignel, B.: A synthesis of the timescale variability of commonly used climate indices using continuous wavelet transform, Global Planet. Change, 78, 1-13, doi:10.1016/j.gloplacha.2011.04.008, 2011.

Schneider, U., Fuchs, T., Meyer-Christoffer, A., and Rudolf, B.: Global Precipitation Analysis Products of the GPCC, Global Precipitation Climatology Centre (GPCC), DWD, Internet Publication, available at: http://www.dwd.de, 1-12, 2008.

Seo, K. W., Waliser, D. E., Tian, B. J., Famiglietti, J. S., and Syed, T. H.: Evaluation of global land-to-ocean fresh water discharge and evapotranspiration using space-based observations, J. Hydrol., 373, 508-515, doi:10.1016/j.jhydrol.2009.05.014, 2009.

Sheffield, J., Goteti, G., and Wood, E. F.: Development of a 50-year high-resolution global dataset of meteorological forcings for land surface modeling, J. Climate, 19, 3088-3111, 2006.

Shiklomanov, A. I., Lammers, R. B., and Vörösmarty, C. J.: Widespread decline in hydrological monitoring threatens PanArctic Research, Eos, Transactions American Geophysical Union, 83, 13, doi:10.1029/2002EO000007, 2002.

Swenson, S. and Wahr, J.: Post-processing removal of correlated errors in GRACE data, Geophys. Res. Lett., 33, L08402, doi:10.1029/2005GL025285, 2006.

Syed, T. H., Famiglietti, J. S., and Chambers, D. P.: GRACEBased Estimates of Terrestrial Freshwater Discharge from Basin to Continental Scales, J. Hydrometeorol., 10, 22-40, doi:10.1175/2008JHM993.1, 2009.

Syed, T. H., Famiglietti, J. S., Chambers, D. P., Willis, J. K., and Hilburn, K.: Satellite-based global-ocean mass balance estimates of interannual variability and emerging trends in continental freshwater discharge, Proc. Natl. Ac. Sci. USA, 107, 1791617921, doi:10.1073/pnas.1003292107, 2010.

Tapley, B. D., Bettadpur, S., Watkins, M. M., and Reigber, C.: The gravity recovery and climate experiment; mission overview and early results, Geophys. Res. Lett., 31, L09607, doi:10.1029/2004GL019920, 2004. 
Trenberth, K. E., Smith, L., Qian, T. T., Dai, A., and Fasullo, J.: Estimates of the global water budget and its annual cycle using observational and model data, J. Hydrometeorol., 8, 758-769, doi:10.1175/JHM600.1, 2007.

Vinukollu, R. K., Sheffield, J., Wood, E. F., Bosilovich, M. G., and Mocko, D.: Multi-model analysis of Energy and Water Fluxes: Intercomparisons between Operational Analyses, Land Surface Model and Remote Sensing, J. Hydrometeorol., 13, 326, doi:10.1175/2011JHM1372.1, 2011.

Wahr, J., Swenson, S., Zlotnicki, V., and Velicogna, I.: Timevariable gravity from GRACE: First results, Geophys. Res. Lett., 31, L11501, doi:10.1029/2004GL019779, 2004.

Wijffels, S. E., Willis, J., Domingues, C. M., Barker, P., White, N. J., Gronell, A., Ridgway, K., and Church, J. A.: Changing Expendable Bathythermograph Fall Rates and Their Impact on Estimates of Thermosteric Sea Level Rise, J. Climate, 21, 56575672, doi:10.1175/2008JCLI2290.1, 2008.
Willmott, C. J. and Matsuura, K.: Terrestrial air temperature and precipitation: monthly and annual time series (1900-2008), V2.01, Center of Climatic Research, University of Delaware, 2010.

Xie, P. P. and Arkin, P. A.: Global precipitation: A 17-year monthly analysis based on gauge observations, satellite estimates, and numerical model outputs, B. Am. Meteorol. Soc., 78, 2539-2558, 1997.

Yu, L. and Weller, R. A.: Objectively analyzed air-sea heat fluxes for the global ice-free oceans (1981-2005), B. Am. Meteorol. Soc., 88, 527-539, doi:10.1175/BAMS-88-4-527, 2007. 